Relations industrielles

Industrial Relations

\title{
La grève des chauffeurs
}

\section{Émile Gosselin}

Volume 13, numéro 3, juillet 1958

URI : https://id.erudit.org/iderudit/1022426ar

DOI : https://doi.org/10.7202/1022426ar

Aller au sommaire du numéro

Éditeur(s)

Département des relations industrielles de l’Université Laval

ISSN

0034-379X (imprimé)

1703-8138 (numérique)

Découvrir la revue

Citer ce document

Gosselin, É. (1958). La grève des chauffeurs. Relations industrielles / Industrial Relations, 13(3), 330-332. https://doi.org/10.7202/1022426ar
Résumé de l'article

Les propos qui suivent sur la dieselisation des locomotives et sur le différend qui oppose la Fraternité des Chauffeurs et Mécaniciens de Locomotives et les grandes compagnies de transport ferroviaire du Canada continuent d'être d'une brûlante actualité.
Tous droits réservés @ C Département des relations industrielles de l’Université Laval, 1958
Ce document est protégé par la loi sur le droit d'auteur. L’utilisation des services d'Érudit (y compris la reproduction) est assujettie à sa politique d'utilisation que vous pouvez consulter en ligne.

https://apropos.erudit.org/fr/usagers/politique-dutilisation/ 


\section{COMMENTAIRES}

\section{La grève des chauffeurs}

\section{Emile Gosselin}

Les propos qui suivent sur la dieselisation des locomotives et sur le différend qui oppose la Fraternité des Chauffeurs et Mécaniciens de Locomotives et les grandes compagnies de transport ferroviaire du Canada continuent d'être d'une brûlante actualité.

Le litige qui oppose la Fraternité des Chauffeurs et des Mécaniciens de Locomotives et la Compagnie du Pacifique Canadien est né le jour où la compagnie a demandé l'abolition des règles, coutumes, pratiques ou accords établis qui exigeaient l'emploi de chauffeurs sur les locomotives mues autrement que par la vapeur, et qu'elle a réclamé le droit absolu de décider à l'avenir de l'emploi de chauffeurs sur les locomotives non mues à la vapeur, en particulier sur les diesels. Voilà, en termes très concrets, l'un des effets logiques de l'introduction de l'automation dans les services ferroviaires. D'où est née la cause-type des chauffeurs de diesels.

Pour voir le problème dans ses perspectives véritables et discuter de ses effets probables, il faut tout d'abord se rendre compte que le conflit n'est pas typiquement canadien, mais qu'il se pose avant tout à l'échelle nord-américaine, sinon mondiale. En outre, ce différend implique fondamentalement, non seulement les chauffeurs, mais d'autres catégories d'employés ferroviaires. Il remet en cause les combinaisons, désormais accessibles à la compagnie, des diverses catégories de maind'oeuvre, à la faveur des récents progrès technologiques, en particulier dans le domaine de l'électronique.

Le différend ouvrier qui fait aujourd'hui manchette oppose la Fraternité des Chauffeurs et Mécaniciens de Locomotives, affiliée depuis le mois d'octobre 1956 au Congrès du Travail du Canada, et la Compagnie de chemin de fer du Pacifique Canadien. La Fraternité groupe des chauffeurs et mécaniciens à l'emploi de près de $150 \mathrm{com}$ pagnies ferroviaires des Etats-Unis et du Canada, alors que la Compagnie du Pacifique Canadien monopolise, avec les Chemins de Fer Nationaux qui se trouvent impliqués dans un différend de même nature, le transport ferroviaire au Canada, en plus de s'assurer une forte tranche du transport aux Etats-Unis. Ajoutons que nos compagnies ferroviaires, et en particulier la compagnie du Pacifique Canadien, exercent une forte influence sur le transport aérien et maritime sur nos routes tant nationales qu'internationales. 
Le réseau ferroviaire canadien s'intègre à un cadre économique bien articulé de transport couvrant les pays nord-américains. Malgré le grand nombre de compagnies ferroviaires qui se font concurrence, il reste que toutes ensemble, elles cherchent à présenter un front uni à la concurrence qui leur vient des transports routiers, maritimes et aériens des divers pays.

Les tarifs souvent non concurrentiels imposés par les diverses commissions étatiques pour les différents modes de transport créent une certaine rigidité dans les sources de revenu, alors que la concurrence force les diverses compagnies à réduire leurs coûts d'opération, leur rendant ainsi souvent difficile une hausse du coût de la main-d'oeuvre. Dès ce moment, un progrès technologique susceptible de réduire les effectifs, de hausser la productivité, donc de diminuer les coûts de façon appréciable sera accepté par l'entrepreneur. Mais dans un système de transport continental intégré, tout changement introduit par une compagnie sera adopté par l'ensemble à brève échéance. D'où l'introduction de la locomotive diesel sans chauffeur dans les cours de triage et sur les trains de marchandises, objet du litige en cours.

Un conflit à la dimension d'un continent ne peut qu'appeler des solutions susceptibles d'application à l'échelle même du continent. Il ne s'agit pas ici d'un différend qui oppose des sujets canadiens dominés par des intérêts étrangers, que ces Canadiens optent pour le point de vue patronal ou syndical. Au contraire! Nous sommes en face d'un règlement de compte familial, dans une famille qui ne connaît que les frontières d'une région économique qui s'appelle un continent, et non pas les frontières politiques. A cette famille appartiennent près de 150 compagnies ferroviaires dont le Pacifique Canadien, et une multitude de syndicats ferroviaires, dont la Fraternité des cheminots. Tous les membres sont vitalement intéressés au conflit en cours et à la solution que l'on y apportera.

Au cours de l'année 1956, toutes les compagnies ferroviaires signant des ententes collectives aux Etats-Unis tentaient de faire éliminer les chauffeurs sur les locomotives diesel. La question ne dépassa pas le stade d'une simple enquête faite par un officier du Bureau fédéral du travail des Etats-Unis, et il n'y eut pas conciliation. Le 21 novembre 1956, toutes les compagnies ferroviaires et la Fraternité signaient un contrat de 3 ans devant expirer vers la fin de 1959. On décidait de conserver les chauffeurs pour l'instant, quitte à adopter probablement comme modèle le règlement qui s'effectuerait au Canada.

Entre-temps, les Chemins de fer Nationaux canadiens décidaient pour leur part de garder leurs chauffeurs à leur emploi, et il restait à la compagnie du Pacifique Canadien de tenter l'expérience et de tracer la voie à l'ensemble des opérateurs ferroviaires du continent.

Les conditions étaient favorables pour les deux parties: la Fraternité des cheminots avaient obtenu des règlements favorables aux Etats- 
Unis et au Canada. D'autre part, la Compagnie s'appuyait sur le rap. port Anderson déposé le 17 décembre 1956, qui déclarait inutile l'emploi des chauffeurs sur les locomotives diesel dans les cours de triage et sur les trains de marchandises. La Fraternité des Chauffeurs venait de se joindre au Congrès du Travail du Canada et pouvait compter sur l'appui des autres syndicats ferroviaires. Et ce furent les grèves de janvier 1957 et de mai 1958, deux étapes d'un mème arrèt de travail originant d'un même conflit. La première phase comportait un arrêt total des services ferroviaires de la Compagnie du Pacifique Canadien et se terminait par la nomination de la Commission Royale Kellock. La deuxième phase débutait le 11 mai 1958, par suite du rejet par la Fraternité des conclusions Kellock acceptées par la Compagnie. Elle se poursuit encore.

Le conflit en cours devrait poser un grave problème à nos gouvernants, car en fait ils se sont constitués médiateurs dans un conflit qui n'est pas canadien mais nord-américain dans sa nature véritable et dans ses effets. En vue d'obtenir un règlement qui puisse avoir des effets durables à l'échelle du continent nord-américain, la véritable médiation du conflit devrait être conférée à une Commission groupant des représentants de tous les pays impliqués.

Le fait que la solidarité syndicale se soit effondrée au cours de la grève en cours et que l'on ait assisté au spectacle peu usité d'employés de chemins de fer brisant les lignes de piquetage de cheminots en grève, pose tout le problème du regroupement des forces syndicales ferroviaires. Il est à se demander si là où il y a 16 syndicats ferroviaires, il n'y en a pas quelques-uns de trop. Au cours du Douzième Congrès des relations industrielles de Laval, nous avons abordé ce problème. $^{1}$

Soulignons que pour augmenter ses chances de succès, un syndicat doit bien connaître les mécanismes qui jouent à l'intérieur du marché du travail et que pour réussir, sa structure doit être telle qu'il puisse négocier avec les employeurs à chaque point des mécanismes où les employeurs peuvent affecter le bien-être des travailleurs. Le syndicalisme ferroviaire a cessé d'être un syndicalisme de métier, depuis le 11 mai. Quoi qu'il advienne du syndicat des chauffeurs, il semble bien que la structure syndicale de demain devra s'édifier sur une base industrielle.

Il ne faut pas blâmer les compagnies ferroviaires de s'occuper de Teurs affaires sous l'oeil scrutateur d'un gouvernement soucieux du bien-être public. Mais le peuple canadien pourra difficilement permettre des arrêts prolongés de travail si, faute de réaménagement de leurs structures, les syndicats sont incapables de réduire au minimum les arrêts de travail provoqués par les progrès technologiques.

(Causerie prononcée à Radio-Canada, le 13 mai 1958.)

(1) Changements économiques et transformations syndicales. Québec, 28, rue Ste-Famille: Les Presses Universitaires Laval, 1958. 184 pp. $\$ 3.00$. 